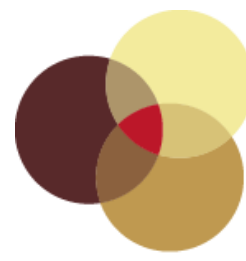

contennporaneity

Vol 7, No 1 (2018) ｜ＩSSN 2153-5914 (online) | DOI 10.5195/contemp/2018.255

http://contemporaneity.pitt.edu

\title{
Football
}

Nick Simko

\section{About the Artist}

Nick Simko is an artist based in Albuquerque, New Mexico. Simko's practice utilizes figurative imagery to navigate cultural processes of identity formation. Simko's work has been exhibited at museums and galleries throughout the United States, including The Vizcaya Museum and Gardens in Miami, The Walters Art Museum in Baltimore, The University of New Mexico Art Museum in Albuquerque, The Tyler School of Art at Temple University in Philadelphia, Colorado Photographic Arts Center in Denver, and Hillyer Arts Space in Washington, DC. In 2018, Simko was one of two artists selected for the Exceptional Visual Scholars Program at the Sanitary Tortilla Factory in Albuquerque. Simko is a 2018 recipient of the Van Deren Coke Fellowship in Photography from the University of New Mexico. Simko holds an MFA in Photography from the University of New Mexico as well as a BFA in Art History, Theory, and Criticism from the Maryland Institute College of Art. 


\section{Football}

Football addresses cultural categories of identity in the context of contemporary portraiture. I started this body of work in 2015 by shooting thousands of photographs of college football players during live sports events. My dad, who guided me in where to get the best shots, was especially delighted, having once been the sports photographer at West Point. I attended football games for three seasons, sitting in the stands and using a 400-millimeter lens to photograph the many figures involved in the spectacle. At the same time I was photographing flora in the studio, and it wasn't until later that I saw that these archives both addressed issues of categorization and naturalness essential to my current practice. In my research, I had been considering the expectations bestowed upon artists who have specific marks of identity, and how their work is expected to authenticate their experience: women should represent their gender, people of color should represent their race, and queer folk should represent their desire. I wanted to problematize this equation by articulating the formation that often privileges itself as the transparent, rectilinear frame through which American culture is often perceived. With this in mind, I selected normative, white, male figures from my archive and extracted them from the din of the football field. Each figure is resituated amid an array of wild flowers, and their uniforms have an unexpected, garish team color. These digital composites are printed at life-size and use a visual vocabulary that hovers between the presumed reality of lens-based photography and the presumed fantasy of digital painting. Depending upon one's physical proximity to the printed pieces, the appearance of the figures and of the flowers shifts from being very stable to very fluid. This project demonstrates that portraiture does not necessarily disclose intrinsic truths about the subject matter it depicts, but rather renders bodies as wildly fluctuating surfaces upon which culture projects, incises, and embeds its ideals. 


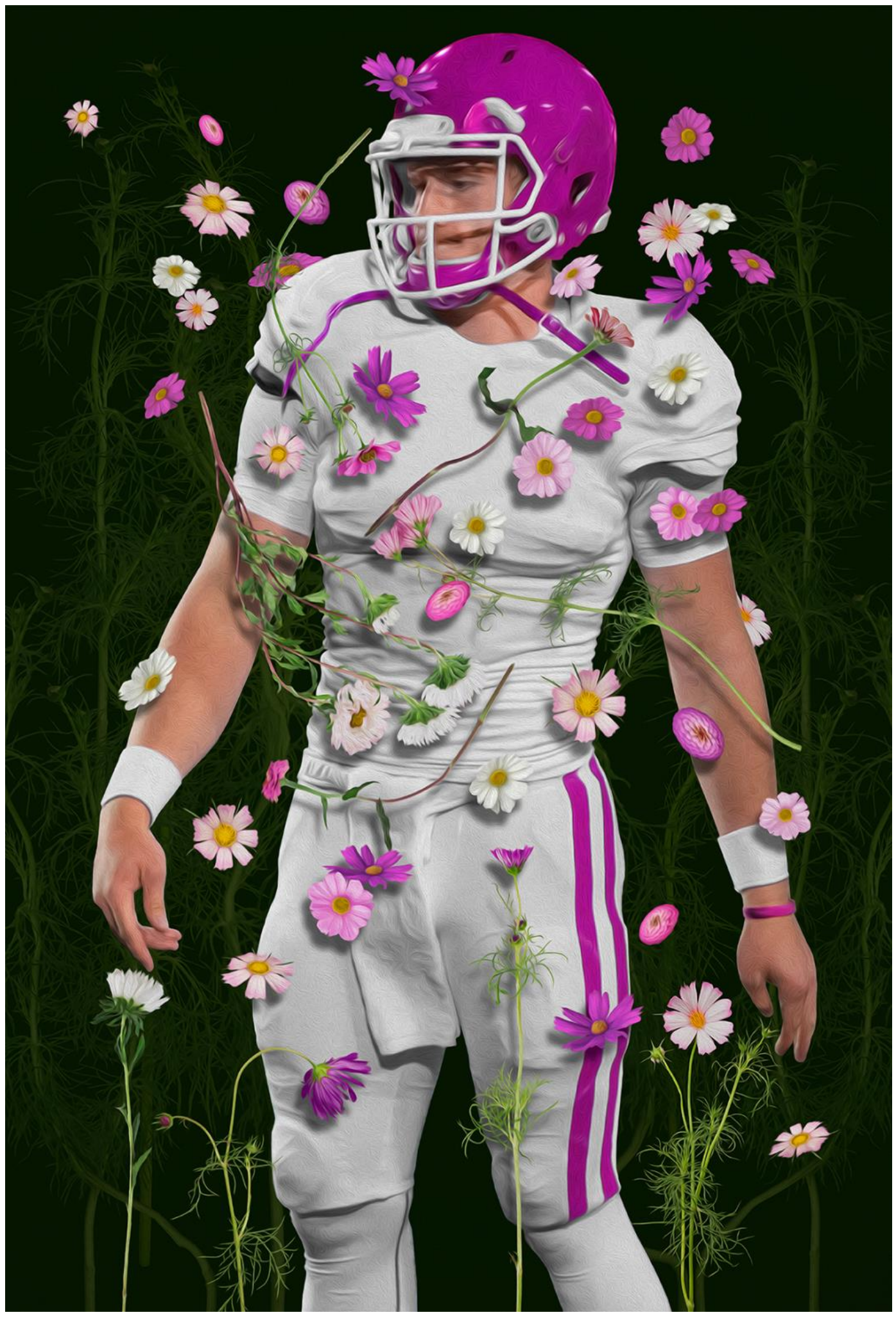

Figure 1

Nick Simko, Football (7), 2018, Digital Composite Photograph, Inkjet Print on Paper, $603 / 4 \times 413 / 4$ in. 


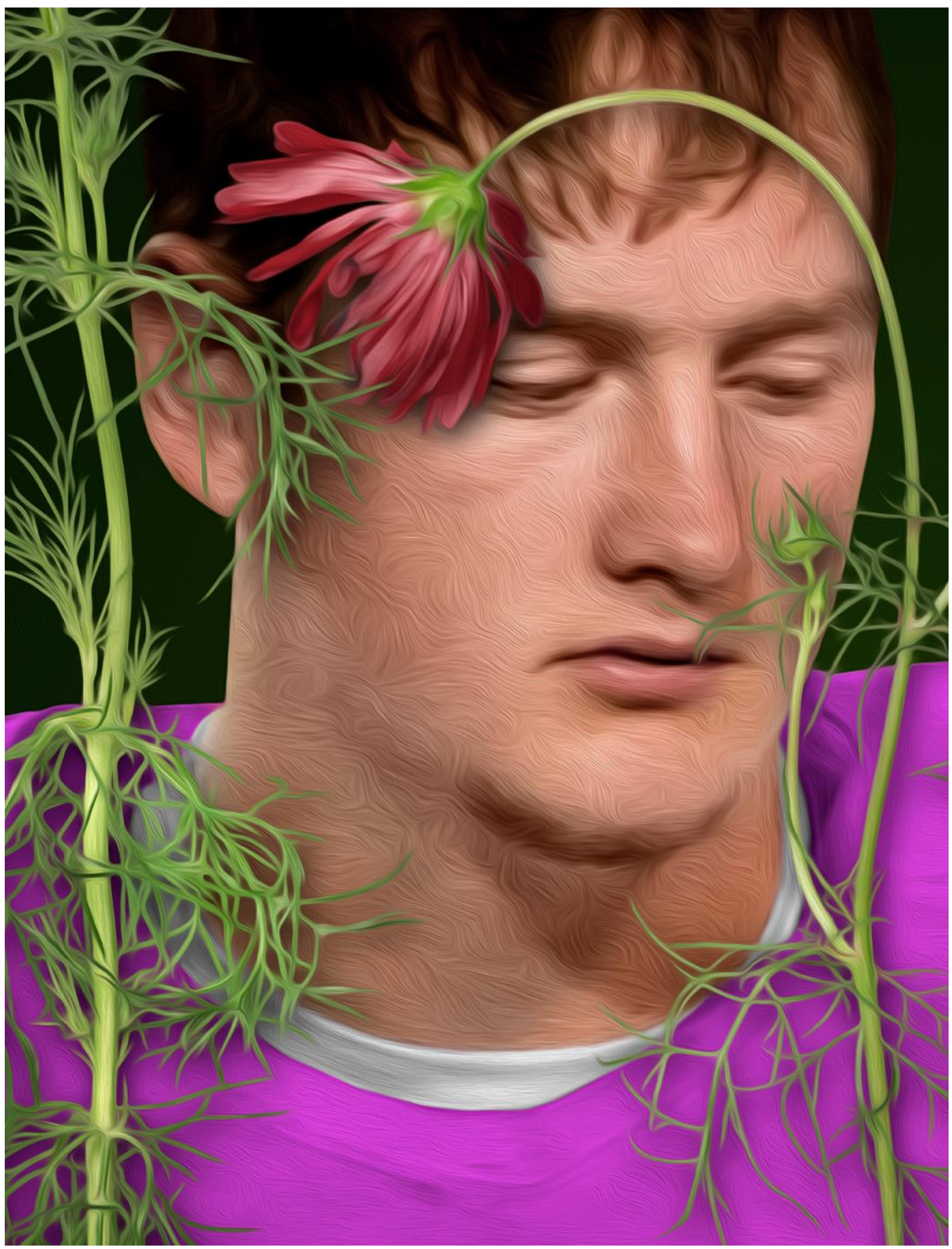

Figure 1

Nick Simko, Football (1), 2018, Digital Composite Photograph, Inkjet Print on Paper, $31 \times 31 \frac{1}{2}$ in. 


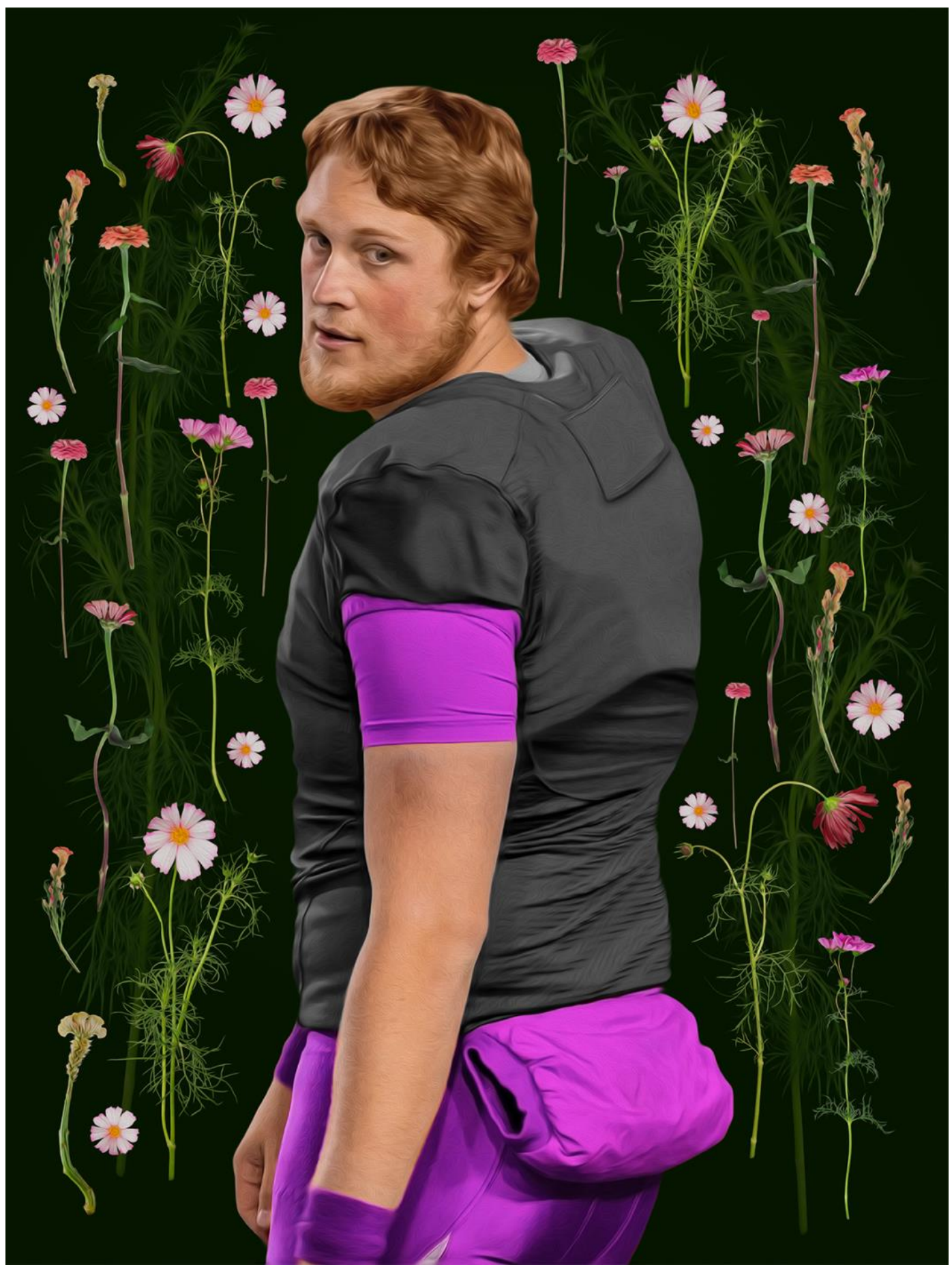

Figure 3

Nick Simko, Football (10), 2018, Digital Composite Photograph, Inkjet Print on Paper, $58 \times 413 / 4$ in. 

4.0 United States License.

\section{ULIS D-Surle}

This journal is operated by the University Library System of the University of Pittsburgh as part of its D-Scribe Digital Publishing Program, and is co-sponsored by the University of Pittsburgh Press. 